\title{
Denys Le Chartreux, Livre de vie des recluses (De Vita Inclusarum)
}

Paris, Beauchesne, 2003, 122 p. (Introduction, trad. et notes par LouisAlbert Lassus, o.p., dossier par le même et Michel Lemoine, avant-propos par Nathalie Nabert) (coll. « Spiritualité carfusienne »)

Jean Séguy

\section{QpenEdition}

\section{Édition électronique}

URL : http://journals.openedition.org/assr/2355

DOI : 10.4000/assr.2355

ISSN : $1777-5825$

Éditeur

Éditions de l'EHESS

\section{Édition imprimée}

Date de publication : 1 avril 2004

Pagination : 47-112

ISBN : 2-222-96746-5

ISSN : 0335-5985

Référence électronique

Jean Séguy, " Denys Le Chartreux, Livre de vie des recluses (De Vita Inclusarum) », Archives de sciences sociales des religions [En ligne], 126 | avril - juin 2004, document 126.56, mis en ligne le 17 novembre 2005, consulté le 21 septembre 2020. URL : http://journals.openedition.org/assr/2355 ; DOI : https:// doi.org/10.4000/assr.2355 
choix des textes, des modes de traductions des

La Preuve par la Chine. La «Description» de J.-B. Du Halde, jésuite, 1735. Paris, Éditions de l'EHESS, 2002, 428 p., (bibliogr., annexes, glossaire, index, illustr.) (coll. « Civilisations et sociétés », 110).

Ce beau livre, issu d'une thèse soutenue en 1999 , est une étude très approfondie d'un monument littéraire, la Description géographique, historique, chronologique, politique et physique de l'empire de la Chine et de la Tartarie chinoise, parue à Paris en 1735. Monument par sa taille (quatre gros volumes), la Description l'est aussi par son influence. L'importance du travail des jésuites en Chine et de leurs publications (recueils de lettres, ouvrages individuels) et leur énorme influence sur les intellectuels européens des $\mathrm{XVII}^{\mathrm{e}}$ et $\mathrm{XVIII}^{\mathrm{e}}$ siècles sont maintenant bien connues des historiens des idées, et beaucoup ont noté le rôle qu'y joue la Description. Euvre relativement tardive, elle a servi d'encyclopédie, reprenant de façon systématique de nombreuses informations publiées par les jésuites de Chine dans le siècle et demi précédent (rappelons que le premier d'entre eux, Matteo Ricci, arrive en Chine en 1583), et a constitué une référence pour de nombreux intellectuels, qu'ils soient sinophiles ou sinophobes, jusqu' au XIX ${ }^{\mathrm{e}}$ siècle.

Cependant, en dépit de son importance, il existait peu de travaux sur la Description prise en elle-même. C'est précisément ce à quoi se livre l'auteur: une étude très minutieuse de la fabrication de l'ouvrage et des sens implicites dans son plan, son argumentation et ses choix éditoriaux, ou encore selon les termes de I.L.-D, de son «secret de fabrication». L'éditeur, Jean-Baptiste Du Halde est lui-même parisien, et n'a jamais été en Chine : il travaille à partir des documents que lui a envoyés de Chine un groupe de vingt-sept collaborateurs jésuites, presque tous français (les autres jésuites de Chine ne sont presque pas utilisés). L'A. réhabilite J.-B. Du Halde, souvent accusé de plagiat, et suit minutieusement son travail de choix, de compilation et d'édition des matériaux. Elle montre surtout que l'ouvrage n'est pas un compendium d'informations sur la Chine (même s'il a surtout été utilisé ainsi), mais bien plutôt une démonstration, visant à fournir des arguments au camp jésuite dans la querelle des rites qui allait peu après, en 1742, être tranchée (contre les positions jésuites d'accommodement de l'apostolat avec les rites funéraires et les cultes d'État chinois). L'interdiction ayant été promulguée en 1710 de publier au sujet de la querelle des rites sous peine de censure, Du Halde n'en parle pas explicitement, mais I.L.-D montre bien que le principales notions, des sujets développés ou au contraire volontairement passés sous silence et du plan même de la Description ne peuvent se comprendre que selon une argumentation sousentendue.

L'A. est sinologue, et fournit un travail de reconstitution des sources chinoises de la Description. Le présent livre, cependant, n'a pas pour sujet la religion en Chine ou la rencontre des jésuites et des Chinois: c'est surtout un travail d'histoire intellectuelle et religieuse de la France au XVIII ${ }^{\mathrm{e}}$ siècle, maniant avec érudition les contextes intellectuels et politiques où évoluent l'auteur et les lecteurs de la Description.

Vincent Goossaert.

Livre de vie des recluses (De Vita Inclusarum). Paris, Beauchesne, 2003, 122 p. (Introduction, trad. et notes par Louis-Albert Lassus, o.p., dossier par le même et Michel Lemoine, avant-propos par Nathalie Nabert) (coll. « Spiritualité carfusienne»).

L'ouvrage ici présenté traduit, avec Introduction et notes explicatives, le De Vita Inclusarum $\left(\mathrm{XV}^{\mathrm{e}}\right.$ siècle). La présence de cette lecture de dévotion dans le présent Bulletin bibliographique peut surprendre. Elle procure l'occasion de signaler à nos lecteurs sociologues ou historiens du christianisme que l'inclusat, que beaucoup tenaient pour disparu il n'y a guère, vit toujours au $\mathrm{XXI}^{\mathrm{e}}$ siècle. Les notes, l'Introduction, l'Avant-Propos rappellent d'ailleurs brièvement les étapes notoires d'une histoire de la vie érémitique (solitaire ou communautaire) en Occident, depuis Romuald de Ravenne, fondateur en première moitié du $\mathrm{XI}^{\mathrm{e}}$ siècle et dans les Apennins de l'ordre des camaldules : celui-ci - peu prospère mais qui existe toujours combine l'érémitisme collectif et l'érémitisme d'individus isolés, auquel s'ajoute le reclusat. On le sait, l'histoire de l'érémitisme collectif se poursuit - après la fondation romualdienne et une cinquantaine d'années plus tard - par la création de l'Abbaye de la Grande Chartreuse et de l'ordre (masculin et féminin) des chartreux. Par certains de ses aspects et au $\mathrm{XI}^{\mathrm{e}}$ siècle, le désir réapparu alors, et en Occident, de solitude érémitique constitue une protestation - cela se vérifiera aussi dans la naissance de Cîteaux et de l'ordre cistercien - à l'encontre de Cluny et de ce que certains nomment alors son « affadissement spirituel». 
La traduction de l'opuscule de l'auteur, écrit à la demande et à l'usage d'une recluse (anonyme), ainsi que l'histoire postérieure des rapports entre camaldules, chartreux, ermites et recluses de toutes descriptions, nombreux alors, témoignent que, même réduite au simple échange de correspondances de direction ou d'écrits dévotionnels, la solitude volontaire apparaît susceptible de créer du lien social. Ceci ne devrait pas être oublié : il existe des groupements d'individus à distance unis par la seule finalité qu'ils se proposent et susceptibles de modes variés - parfois fort légers - d'organisation. G. Gurvitch avait en son temps évoqué cette possibilité (cf. La Vocation de la sociologie, Paris, PUF, 1957, t.1, p. 316 et passim).

On trouvera, à la suite du Livre de la vie des recluses, une courte anthologie (c'est le «dossier » évoqué par le «sous-titre ») de textes ou d'extraits de quelques auteurs médiévaux ayant traité du reclusat. L'Introduction et les indications bibliographiques dispersées dans l'ouvrage indiquent aussi des noms de recluses ou de reclus contemporains. On le constate en l'occurrence, l'individualisme de la piété n'est pas d'aujourd'hui : il a une histoire, au passé comme au présent. Une parution récente (Éloge de l'enfouissement, par un ermite camaldule ; présenté par L.-A. Lassus, o.p., Paris, Parole et Silence, 2002) démontre par sa seule existence que l'attrait pour le silence et la culture d'un individualisme radical persiste dans le cadre du catholicisme contemporain.

\section{Jean Séguy.}

\subsection{7}

LEHMANN (Rosa).

Symbiosis And Ambivalence. Poles And Jews In A Small Galician Town. New YorkOxford, Berghahn Books, 2001, 217 p. (bibliogr., index, cartes).

À partir de documents d'archives, d'interviews d'habitants actuels de Jasliska - la petite ville de Galicie où l'auteure a mené son enquête - et de survivants juifs, anciens habitants du lieu, dispersés entre l'Europe, l'Amérique et Israël, R.L. s'attache à démontrer que les relations qu'entretenaient les juifs et les Polonais dans les petites localités rurales de la Pologne d'avant-guerre, étaient constituées d'un entrelacs serré d'activités, de rapports interpersonnels et d'intérêts, de proximité résidentielle et d'interdépendance, de sentiments et d'émotion, infiniment plus complexes et ambivalents que ne le laisse supposer la vision traditionnelle, binaire et tranchée, opposant les Polonais antisémites d'un côté et les juifs victimes de l'autre. Pour mener à bien sa démonstration, elle présente l'historique de la présence juive à Jasliska ; elle décrit la disposition et l'évolution spatiales de la présence juive; elle analyse des relations économiques faites de dépendance, de compétition et d'hostilité ; elle analyse la dimension culturelle et religieuse des échanges. Au lendemain de la destruction du judaïsme polonais, dont les différentes étapes sont décrites, la réalité de la vie juive a cédé la place aux représentations, seul mode d'accès au monde juif désormais offert aux générations de Polonais nés après la guerre. C'est précisément l'ambivalence de ces représentations qu'a pu observer l'A. à Jasliska.

Régine Azria.

126.58

MALKA (Salomon).

Jésus rendu aux siens. Enquête en Israël sur une énigme de vingt siècles. Paris, Albin Michel, juin 1999, 227 p. (glossaire, bibliogr.).

S.M. nous propose une véritable visite guidée en Israël sur les traces de Jésus. L'ouvrage commence par l'aventure de la découverte des fameux manuscrits de la Mer morte à Qumran: Jésus était-il membre du groupe qui vivait là ? que nous apprennent les manuscrits sur sa vie?

L'auteur part à la recherche des paysages qu'a connus Jésus, et à l'écoute des savants, juifs d'aujourd'hui, qui ont passé leur vie à travailler sur lui, sur l'époque de la naissance du christianisme : " comment, se demande l'A, perçoit-on la figure du Nazaréen dans ce pays qui l'a vu naître ?».

L'ouvrage est une synthèse passionnante des entretiens de S.M. avec les plus éminents spécialistes de cette période : Geza Vermès qui insiste sur l'aspect pluraliste de la communauté juive d'alors, David Satran pour qui il n'y a pas de lien direct entre Qumran et Jésus mais entre Qumran et Jean le Baptiste, Daniel Shwartz pour qui Jésus est un zélote qui a voulu libérer son peuple des occupants romains, tous et d'autres, pour qui Jésus est un juif, qui a vécu en juif, respectueux des mitsvoth comme les pharisiens dont il faisait partie.

Le chapitre le plus surprenant de l'ouvrage concerne le procès de Jésus. L'A nous apprend que quatre mois après la naissance de l'État, et de nombreuses fois dans les années qui suivirent, des chrétiens à travers le monde, quelques juifs aussi, ont écrit aux juges de la Cour Suprême d'Israël pour leur demander...la révision du Procès de Jésus : demandant à la Cour, nouvellement installée dans le pays à nouveau gouverné par des juifs, de jouer le rôle d'une 